\title{
Design de Carenagem de um Sistema de Propulsão Submergível Para Embarcação Movida por Energia Solar
}

\author{
Fairing Design of A Submersible Propulsion System Of A Boat Powered by Solar \\ Energy
}

SPERANDIO, Debora Eloise; Graduanda; Instituto Federal de Santa Catarina debsperandioo@gmail.com

TAKASO, Jessica Haruka; Graduanda; Instituto Federal de Santa Catarina

jessicatakaso@gmail.com

SCOLARI, Sérgio Henrique Prado; Doutorando; Instituto Federal de Santa Catarina

sergio.scolari@ifsc.edu.br

\section{Resumo}

A energia solar é uma fonte limpa, renovável e de aplicação versátil. Em embarcações, seu uso depende de painéis fotovoltaicos, que transformam a luz solar em fonte energética e alimentam diversos sistemas. Anualmente, a equipe do Instituto Federal de Santa Catarina participa do Desafio Solar Brasil, um rali que incentiva a inovação tecnológica na área. Para manter-se competitiva, a equipe precisa atualizar o sistema propulsivo de seu barco, operado a seco, para um submergível. Nesse sentido, este artigo relata o desenvolvimento da carenagem para o sistema de encapsulamento do novo motor. O processo foi estruturado pelo Método de Desdobramento em Três Etapas, complementado por ferramentas metodológicas como Análise da Tarefa, Análise de Similares, Grupo Focal, Brainstorming e Biônica. Como resultado tem-se uma carenagem hidrodinâmica, de fácil manutenção, montagem e desmontagem, e que conta com uma estrutura modular pensada para cenários competitivos.

Palavras Chave: Design de Produto; Carenagem; Barco Solar

\begin{abstract}
Solar energy is a clean and renewable source of energy with versatile application. In boats, its use depends on photovoltaic panels that transform sunlight into an energy source that feeds several systems. Annually, the Instituto Federal de Santa Catarina's team participates in the Desafio Solar Brasil, a rally that encourages technological innovation in the area. In order to stay competitive, the team needs to upgrade its dry-driven propulsive system to a submersible one. In this sense, this article describes the development of the fairing for the encapsulation system of the new engine. The process was structured by the Método de Desdobramento em Três Etapas, complemented by methodological tools such as Task Analysis, Similar Analysis, Focus Group, Brainstorming and Bionics. As a result there is a hydrodynamic fairing, easy maintenance, assembly and disassembly, and that has a modular structure designed for competitive scenarios.
\end{abstract}

Keywords: Product Design; Fairing; Solar Boat 


\section{Introdução}

O uso de energia fotovoltaica tem se tornado uma alternativa com "potencial para completar uma grande parte de um total de energia necessária economicamente, de uma maneira segura e sustentável no futuro" (IEA, 2011, p. 23), apresentando versátil aplicabilidade em contextos onde fontes energéticas são necessárias.

Como forma de fomentar o desenvolvimento científico e tecnológico sobre o tema no país dentro do contexto naval, anualmente é promovido o Desafio Solar Brasil (DSB): trata-se de uma competição universitária de rali de barcos movidos por energia solar, visando o desenvolvimento de tecnologias sustentáveis baseados em energias limpas e com maior eficiência para o transporte náutico. Uma das embarcações que competem no Desafio é o da Equipe Zênite do Instituto Federal de Santa Catarina. O barco solar desenvolvido pela Equipe surgiu em 2013, com o intuito de incentivar estudos relacionados à engenharia e à energia sustentável. Atualmente, o projeto conta com uma equipe multidisciplinar que envolve professores e alunos dos cursos de Engenharia Mecatrônica, Engenharia Elétrica, Engenharia Eletrônica, Engenharia Mecânica, Meteorologia e Design de Produto.

O esquema funcional da embarcação, de acordo com Batista et al. (2015), é composto pelos seguintes sistemas: controle, composto por um computador de bordo responsável por controlar a velocidade do motor; painéis fotovoltaicos que transformam a radiação solar em energia elétrica; sistemas de transmissão e distribuição que convertem a energia para níveis compatíveis com consumo; circuitos auxiliares que garantem a segurança e a comunicação da embarcação; motor e todo o sistema mecânico acoplado ao seu eixo, responsáveis pela propulsão do barco.

O sistema propulsivo é responsável pela movimentação e direcionamento do barco, realizados por meio de um esquema mecânico composto por: um motor elétrico de corrente contínua, que opera a seco (não submergível); acoplamentos; elementos de fixação; engrenagens de transmissão mecânica; uma hélice específica para motores elétricos de popa e um leme. Este sistema é funcional, entretanto, apresenta baixa eficiência de desempenho quando comparado com sistemas modernos, visto que o peso e volume de seus componentes são elevados.

Assim, com intuito tornar o barco mais competitivo, propõe-se o desenvolvimento de um sistema de propulsão submergível, com a utilização de um motor de corrente contínua sem escovas (maior densidade de potência) do tipo outrunner (rotaciona a parte externa e mantém o eixo fixo), e um sistema de transmissão mais compacto e eficiente. Com as novas configurações, o sistema demanda a existência de uma carenagem que proteja seus componentes contra efeitos da água salina e possíveis impactos. Ainda, tal carenagem precisa se adequar às diferentes demandas hidrodinâmicas das provas do Desafio, bem como facilitar o processo de montagem e desmontagem para manutenção de seus componentes durante as competições. Para nortear o desenvolvimento do projeto e integrar as equipes envolvidas tomou-se como referência a estrutura metodológica proposta por Santos (2006).

\section{Metodologia}

O método de projeto selecionado foi o Método de Desdobramento em Três Etapas (MD3E) de Santos (2006). Esta escolha deu-se por sua estrutura ser flexível, sem apresentar caminho prédeterminado. Este método estimula interferências ao longo do projeto, permitindo acréscimos, 
retiradas e desdobramentos de etapas. Essas possibilidades foram fundamentais para a efetivação do projeto, que contou com uma equipe multidisciplinar, facilitando a participação e a comunicação entre os integrantes. O método apresenta uma visão circular, iniciando com uma necessidade central, e posteriormente dividindo-se em três grandes etapas: Pré-Concepção, Concepção e Pós-Concepção. Essas etapas, por sua vez, são desdobradas em outras sub-etapas e atividades. $O$ gerenciamento e a documentação do projeto devem ser preocupações constantes do designer ao longo das atividades, assim estas duas tarefas permeiam todas as etapas. Na Figura 1 apresenta-se a estrutura metodológica resultante do projeto.

Figura 1 - Estrutura metodológica do projeto

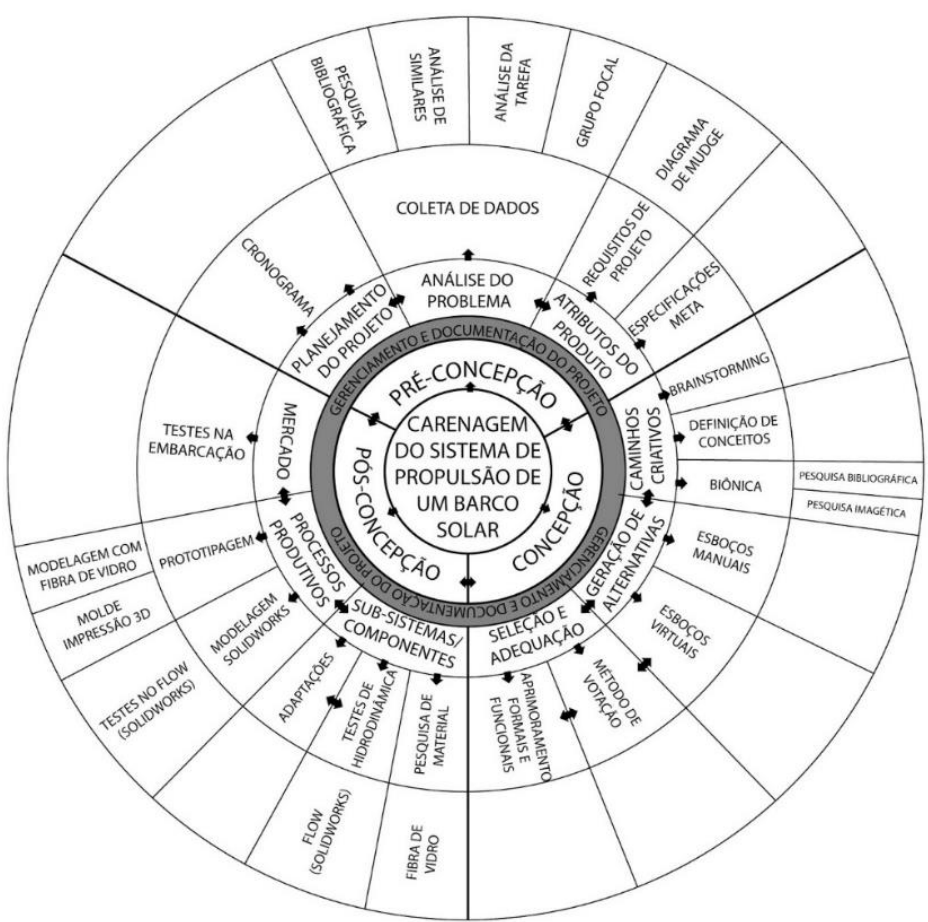

Fonte: Baseado em Santos (2006)

Durante a fase de Pré-Concepção foram realizadas pesquisas bibliográficas sobre o funcionamento da energia elétrica e suas aplicações, embarcações solares e seus determinados sistemas propulsivos. Ainda, realizaram-se uma Análise da Tarefa, conforme descrita em Pazmino (2015), e uma Observação Participante, como em Yin (2005), durante a montagem e desmontagem do sistema atual utilizado na embarcação, a fim de compreender o contexto em que o problema de projeto se encontra; uma Análise de Similares, segundo estabelecido por Baxter (2005), dos sistemas propulsivos submersos encontrados no mercado, comparando-os de maneira a identificar pontos positivos e negativos nos modelos já existentes; e um Grupo Focal, baseado em Pazmino (2015), com os indivíduos envolvidos no projeto de construção do novo sistema propulsivo.

Por fim, foram apontadas as necessidades existentes e gerados requisitos de projeto, hierarquizados através de um Diagrama de Mudge que, de acordo com Nickel et al. (2010), permite a ordenação por relevância. 
Ao longo da etapa de Concepção geraram-se alternativas para a carenagem com auxílio da ferramenta de Brainstorming que, de acordo com Dzindolet (1993), possui o intuito de coletar o maior número de ideias possíveis. Algumas expressões encaminharam um estudo de formas utilizando a Biônica inspirada em animais marinhos. Baseadas neste estudo, mais de 100 alternativas foram geradas, colocadas em votação e refinadas. A alternativa final, por fim, foi redesenhada, dimensionada e construída tridimensionalmente no software. Já na Pós-Concepção foram estudados métodos para prototipagem e materiais para fabricação do molde e modelo final, como fibra de vidro e impressão 3D.

A aplicação de todas as ferramentas mencionadas anteriormente foi possível em virtude do método aplicado, que permite utilizar diferentes ferramentas e abordagens a fim de auxiliar no processo de desenvolvimento do produto. Todas as três etapas do projeto foram documentadas durante sua realização, possibilitando um acompanhamento dos processos e pesquisas por todas as equipes envolvidas no projeto. As etapas do processo são detalhadas a seguir.

\section{Desenvolvimento: Pré-Concepção}

Segundo o Método de Desdobramento em Três Etapas, é na etapa inicial que se definem todas as atividades de projeto e, em seguida, feitas as buscas na literatura e/ou aplicadas ferramentas auxiliares para seu desdobramento. Para o desenvolvimento da carenagem, os trabalhos iniciaram-se por meio de pesquisas bibliográficas sobre a energia solar como alternativa para combustíveis a base de petróleo em embarcações e sobre o funcionamento dos barcos solares, aliadas a uma imersão junto à equipe responsável pelo barco a fim de investigar as necessidades de Design envolvidas.

A partir do panorama encontrado, elegeram-se outras 3 ferramentas de coleta de dados para alimentar a lista de requisitos de projeto antes da fase de Concepção, a saber: Análise de Similares, Análise da Tarefa aplicada a uma Observação Participante e Grupo Focal. As características dessas ferramentas e como sua utilização contribuiu para este projeto são discutidas nos itens 3.1, 3.2, e 3.3. Para finalizar a etapa de Pré-Concepção as informações advindas da coleta de dados são sistematizadas e hierarquizadas, resultando nas Necessidades e Requisitos de Projeto, descritos no item 3.4.

\subsection{Análise Da Tarefa No Sistema de Propulsão Atual do Barco Solar}

Segundo PAZMINO (2015) a ferramenta de Análise da Tarefa envolve observar, descrever e detectar pontos negativos e positivos existentes na relação entre o indivíduo e o produto, analisando a usabilidade e o manejo quanto ao produto ou serviço. Esta atividade foi responsável por detectar problemas específicos enfrentados no sistema atual, a fim de aprimorá-los no desenvolvimento da nova carenagem. Simultaneamente, foi realizada uma Observação, que, de acordo com Oliveira (2011), também é um meio de coleta de dados para adquirir informações sobre aspectos específicos de determinada situação. Neste caso, realizou-se uma uma Observação Participante, onde os observadores assumiram funções dentro do estudo de caso, uma vez que desta forma, de acordo com Yin (2005), o pesquisador deixa de ser um observador passivo e passa a perceber a realidade da situação do ponto de vista de alguém que está inserido na atividade estudada. 
A Observação Participante aconteceu no dia 06 de maio de 2017, no Lagoa late Clube, dàs 9 da manhã às 17 horas. A equipe de Design acompanhou o processo de montagem do sistema de propulsão do barco, realizado para um teste de funcionamento na água, com critérios da própria equipe e diretrizes do Desafio Solar Brasil. Durante a montagem do sistema de propulsão (Figura 2) foi considerado o tempo necessário para realizar tal etapa, a facilidade ou dificuldade em realizar as tarefas pelos integrantes para acoplar o motor, a hélice e os demais componentes, e o manuseio e distribuição das peças e ferramentas.

Figura 2 - Acoplagem de peças do sistema mecânico
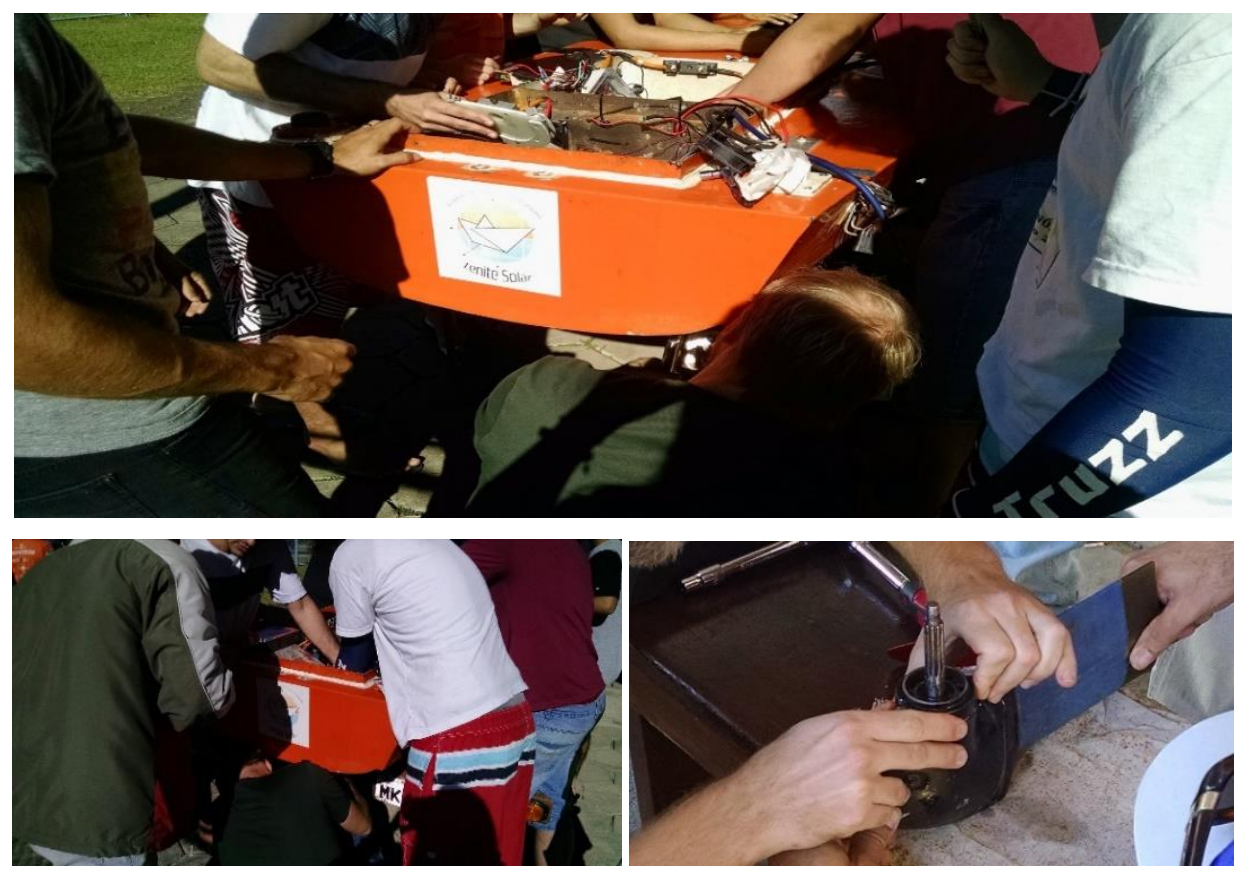

Fonte: Autoria própria (2017)

As anotações de registro desta atividade contemplaram as dificuldades de montagem, percebidas pela equipe de Design, e conversas com os alunos presentes no processo de montagem dos componentes, que relataram suas percepções sobre e compartilharam suas experiências durante competições passadas. Estas anotações foram, posteriormente, analisadas e transcritas em um arquivo digital.

Com a conclusão das análises, foi possível identificar problemas que abrangem o montar e desmontar das peças, que permitiram sugerir algumas diretrizes para o encaminhamento do projeto: a) redução da quantidade de etapas e peças que envolvem sua construção, facilitando a montagem e desmontagem; b) priorização de encaixes intuitivos, visto que a falta de identificação de peças causa perda de tempo; e c) a implementação de esquemas informacionais, como identificações visuais nas interfaces. Estas estratégias podem contribuir para auxiliar na diminuição do tempo de montagem geral durante a competição, garantindo maior tempo para checagem de eventuais problemas.

\subsection{Análise de Similares}

Segundo Baxter (2005), a Análise de Similares é uma ferramenta de investigação e coleta 
de dados de determinados produtos, empresas ou áreas, e é utilizada em processos de desenvolvimento de projeto para diferenciar o produto em desenvolvimento daqueles já existentes no mercado. Nesse sentido, foram selecionados alguns modelos similares de sistemas de propulsão submersíveis (Figura 3) encontrados em sites de marcas que oferecem esse tipo de equipamento. A escolha desses modelos foi baseada nas características desejadas para o produto, portanto todos são motores elétricos, possuem a hélice posicionada na parte traseira e apresentam lemes. Todos os similares encontrados são estrangeiros, sugerindo que a produção nacional desse tipo de sistema ainda é incipiente e reside no âmbito das instituições de pesquisa.

\section{Quadro 1 - Similares analisados}

Modelos
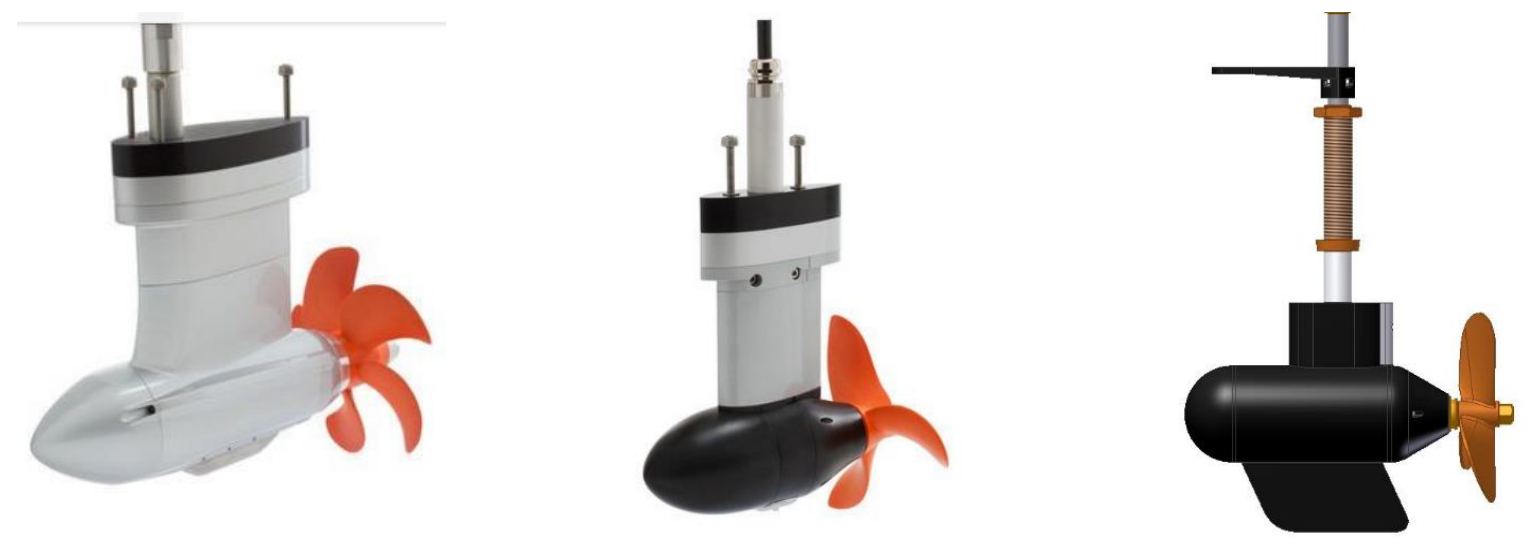

Cruise 10.0 FP (Torqeedo)

Cruise 2.0 FP (Torqeedo)

ACR 4.0 (Außenbord-Elektromotor)

Fonte: Torqeedo e Außenbord-Elektromotor (2017)

Todas as carenagens analisadas possuem forma predominantemente cilíndrica, e os dois modelos da marca Torqeedo possuem a parte frontal em forma cônica, responsáveis por empurrar a embarcação e são feitos com o melhor alumínio contra os efeitos da água salina segundo a fabricante. O primeiro modelo da esquerda para direita, possui leme com maior comprimento e altura, leme inferior e hélice na parte posterior. O segundo modelo possui leme com menor comprimento e maior altura e hélice na parte posterior também. 0 modelo da marca Kräutler Elektromaschinen é feito com alumínio resistente à água salina e diferente dos outros dois modelos, possui a parte frontal em forma de semi-esfera. Observou-se neste modelo, ainda, a opção de distribuir a área do leme, com menor comprimento e menor altura, utilizando também a parte abaixo do corpo da carenagem, a fim de aumentar a eficiência do direcionamento e proteger a hélice de possíveis impactos com o solo. Os materiais utilizados nos produtos similares são alumínios com acabamentos resistentes à água salina, e suas formas de encaixe acontecem por rebaixos pré-determinados e uso de parafusos.

\subsection{Grupo Focal}

A fim de aprofundar o conhecimento sobre as demandas do novo sistema de propulsão, a equipe de Design optou por aplicar a ferramenta Grupo Focal, que de acordo com Pazmino (2015) consiste em uma reunião realizada por um moderador e um grupo de pessoas que representam os 
consumidores-alvo do produto em desenvolvimento. Neste tipo de reunião o moderador deve sempre estimular o grupo a compartilhar ideias gerais e expandir o entendimento sobre o produto em questão. Essa ferramenta se trata de uma pesquisa qualitativa, que permite identificar as necessidades e os desejos dos usuário.

A reunião aconteceu no dia 16 de maio de 2017, às 11 h30 da manhã, em um laboratório do Departamento de Eletrônica do Instituto Federal de Santa Catarina, onde a equipe de Design desempenhou o papel de moderador. O grupo de pessoas convidadas para representar os consumidores foram quatro professores especialistas envolvidos com os projetos do barco solar e dois alunos bolsistas da equipe de Engenharia. Durante o encontro concluiu-se que o motor elétrico seria envolvido por uma cápsula, e que esta cápsula seria protegida pela carenagem em desenvolvimento. $O$ esquema pode ser observado por uma representação digital produzida pela equipe de engenharia (Figura 3):

Figura 3 - Esquema do sistema de encapsulamento do motor

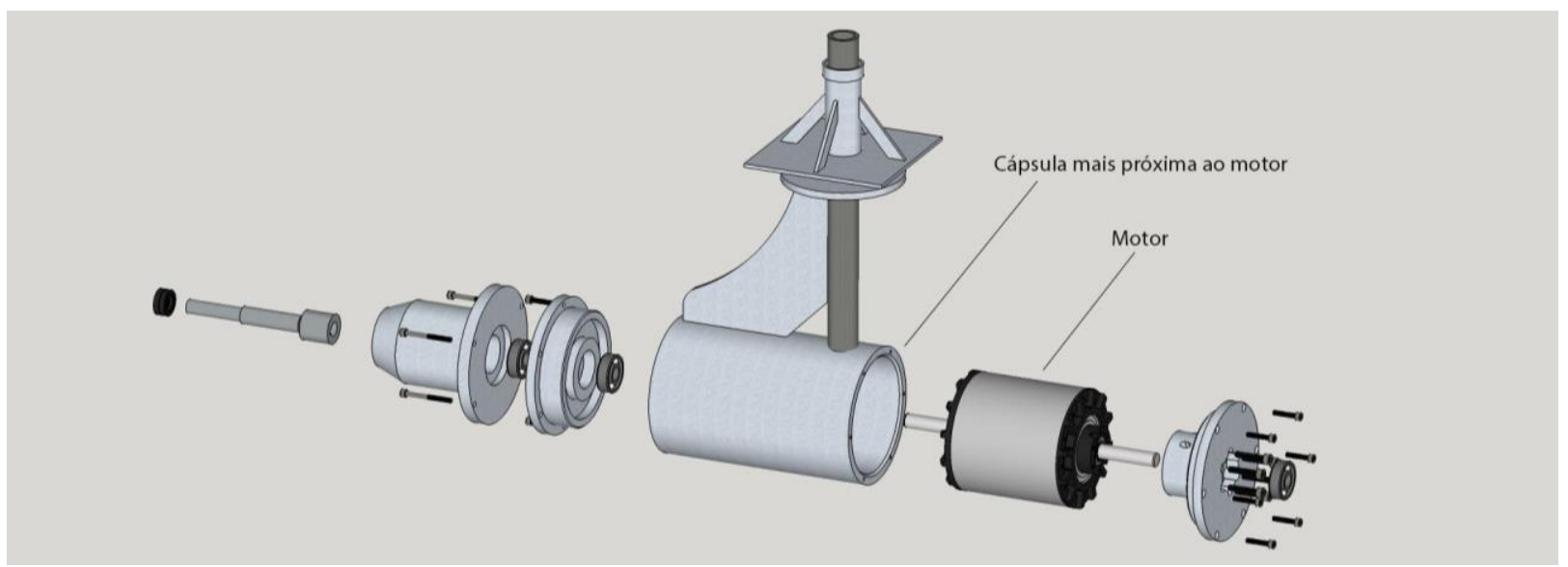

Fonte: Fuerback (2017)

Outro ponto levantado tratou da dissipação térmica do motor. Estabeleceu-se como referência de temperatura máxima $90^{\circ} \mathrm{C}$ no exterior da cápsula, e que a carenagem deveria facilitar a passagem de calor, permitindo a refrigeração com a ajuda da própria água.

O uso da ferramenta Grupo Focal na etapa de coleta de informações além de possibilitar a identificação dos desejos e das necessidades das diferentes equipes de projeto quanto ao produto, contribuiu para a homogeneizar as ideias sobre o que estava sendo projetado, facilitando a comunicação interdisciplinar.

\subsection{Necessidades e Requisitos de Projeto}

Ao final da coleta de dados, classificaram-se cinco necessidades principais, transformadas em requisitos. A atividade de identificar os requisitos é usada para orientar o processo em relação às metas a serem atingidas (PAZMINO, 2010) e auxiliar a equipe a alcançar seu objetivo. Os requisitos foram definidos coletivamente em reunião com todos os integrantes do projeto, e classificados em ordem de prioridade utilizando o Diagrama de Mudge, que permite a comparação de dois em dois requisitos por vez, analisando qual é mais relevante. E ainda é possível valorar cada requisito e analisar o quanto este é mais relevante que o outro. Obtendo-se, dessa forma, 
um ranking, ou hierarquia, dos objetivos e o quanto cada um deles é mais ou menos importante (NICKEL et al., 2010). Deste modo, os 9 requisitos principais foram colocados no quadro, valorados e comparados, com pontuações 5, 3, 1 e 0 (do mais importante para menos importante). A ordem resultante da hierarquização foi:

Quadro 2 - Necessidades e requisitos

\begin{tabular}{ll}
\hline NECESSIDADE & REQUISITO \\
\hline Hidrodinâmico & $\begin{array}{l}\text { 1) Desenvolver aspectos que tornem o envoltório favorável à direção do } \\
\text { movimento da água, de maneira a reduzir o arrasto (31 pontos); }\end{array}$ \\
\hline Proteger e resistir & $\begin{array}{l}\text { 2) Deve possuir resistência à corrosão e à deformação em uso (23 pontos); } \\
\text { 2) Desenvolver um sistema de vedação contra água salina, sujeiras e objetos (23 } \\
\text { pontos); }\end{array}$ \\
\hline
\end{tabular}

Montar e desmontar

3) Conceber o produto com baixa quantidade de peças e formas intuitivas nos encaixes, possuindo baixa complexidade ( 20 pontos);

Direcionamento
4) Impedir que a hélice encoste no fundo do mar (16 pontos);
5) Manter-se alinhado com a direção do barco (9 pontos);
6) Desenvolver um sistema de fácil manipulação do cabeamento da direção (3
pontos);
7) Moldar-se à variação de trim (0 pontos);

Fixação ao madre leme

7) O leme deve ser fixado ao madre leme e encapsulamento de forma a envolvêlos (0 pontos).

Fonte: Autoria própria (2017)

Com esta hierarquização foi possível delimitar as principais funções às quais a carenagem deveria resolver, sendo utilizadas como referências na etapa de Concepção das alternativas.

\section{Desenvolvimento: Concepção}

Segundo o Método de Desdobramento em Três Etapas, esta fase se inicia com a geração de alternativas, definindo o conceito e a forma do produto, e se encerra ao encontrar a solução mais adequada. Para auxiliar no processo criativo foram selecionadas e utilizadas as ferramentas: Brainstorming e Biônica, descritas, respectivamente, nos itens 4.1 e 4.2.

\subsection{Brainstorming}

Brainstorming é uma ferramenta com o objetivo de gerar o maior número de ideias possíveis. Os participantes não devem julgar antecipadamente as ideias, mas sim expor todo pensamento que surgir em suas mentes. Assim, a ideia de um participante estimula a construção de outras ideias por todo o grupo (DZINDOLET, 1993). A constituição de um grande número de ideias irá acarretar em ideias com potencial. A aplicação do Brainstorming nessa fase de projeto auxiliou a iniciar a conceituação do produto e buscar inspirações de formas e princípios de funcionamento, para em seguida gerar as alternativas de solução. 
Uma das palavras mencionadas durante a aplicação da ferramenta foi a "hidrodinâmica", sendo ela o requisito definido como prioritário no projeto. Esta e as demais palavras, portanto, direcionaram a pesquisa para um estudo de organismos vivos existentes na natureza que fossem referência em termos de hidrodinâmica. Iniciando, assim, o estudo de formas através da biônica de tubarões, considerados um dos mais eficientes quando se trata de locomoção na água salina. Esse estudo possui a finalidade de compreender as estruturas formais dos tubarões e como elas se comportam em meio aquático.

\subsection{Biônica: Tubarão Mako}

A natureza oferece uma grande diversidade de estruturas, sistemas e funções, sendo inspiração para o desenvolvimento em muitas disciplinas como química, biologia, física e engenharia (SANCHEZ, et al. 2005). A biônica se define principalmente em compreender e simular as estruturas biológicas, somando com o conhecimento tecnológico desenvolvido pelo homem.

Os tubarões estão entre as espécies marinhas mais eficientes em termos de deslocamento, e por isso selecionados como referência do presente estudo de Biônica. Dentre eles a espécie de tubarão Mako se destacou por ser uma das espécies de natação mais rápida. Apresenta corpo fusiforme (Figura 4), focinho pontiagudo e possui uma grande quilha em sua cauda (COMPAGNO apud COMASSETTO, 2016).

Figura 4 - Tubarão Mako

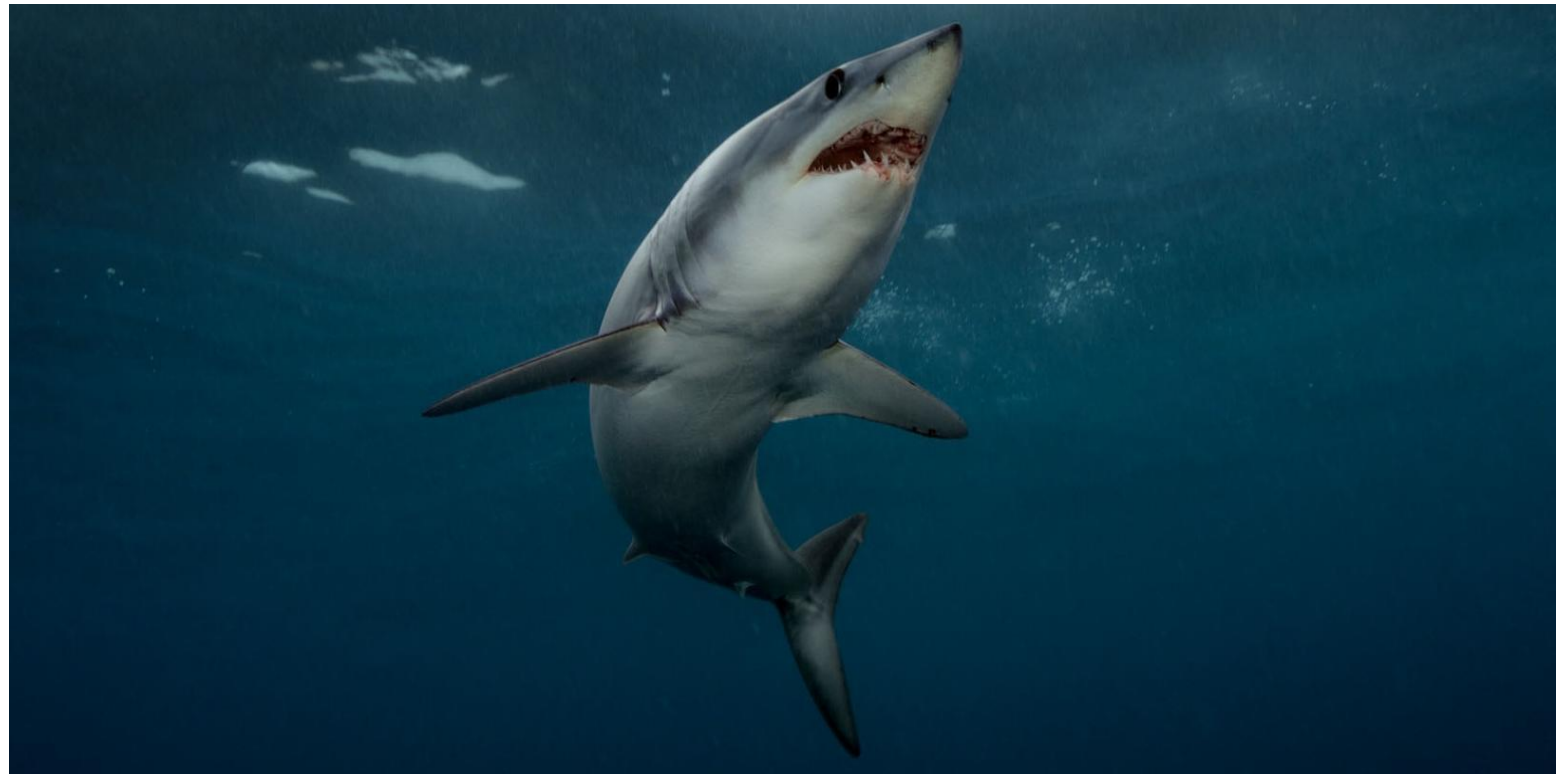

Fonte: Brian Skerry, National Geographic (2016)

A partir das análises, chegou-se à conclusão de que a característica do corpo fusiforme era determinante para o desenho da carenagem, por garantir boa hidrodinâmica. Além disso, as quilhas encontradas nos tubarões, que também estão presentes em pranchas de surf e são essenciais para o seu funcionamento, proporcionam direcionamento e propulsão para as manobras do mesmo, sem perder velocidade (ARAÚJO, 2014), também foi outra característica considerada necessária para estar presente nas alternativas. 


\subsection{Geração, Avaliação e Seleção de Alternativas}

A partir das ferramentas de criatividade, a equipe de Design iniciou a Geração de Alternativas. Com um total de 121 alternativas geradas, as opções foram filtradas através de uma ferramenta de votação, dentro da equipe. Segundo Baxter (2005), votação é uma ferramenta de seleção em que alternativas são avaliadas sobre o quanto solucionam a necessidade do projeto. Existem diversos métodos para realizar a votação, porém neste projeto foram atribuídos 5 votos para cada membro da equipe, a serem distribuídos de forma que uma mesma alternativa pudesse receber mais de um voto da mesma pessoa. Assim, das 121 alternativas existentes, 13 obtiveram pelo menos um voto (Figura 5 ).

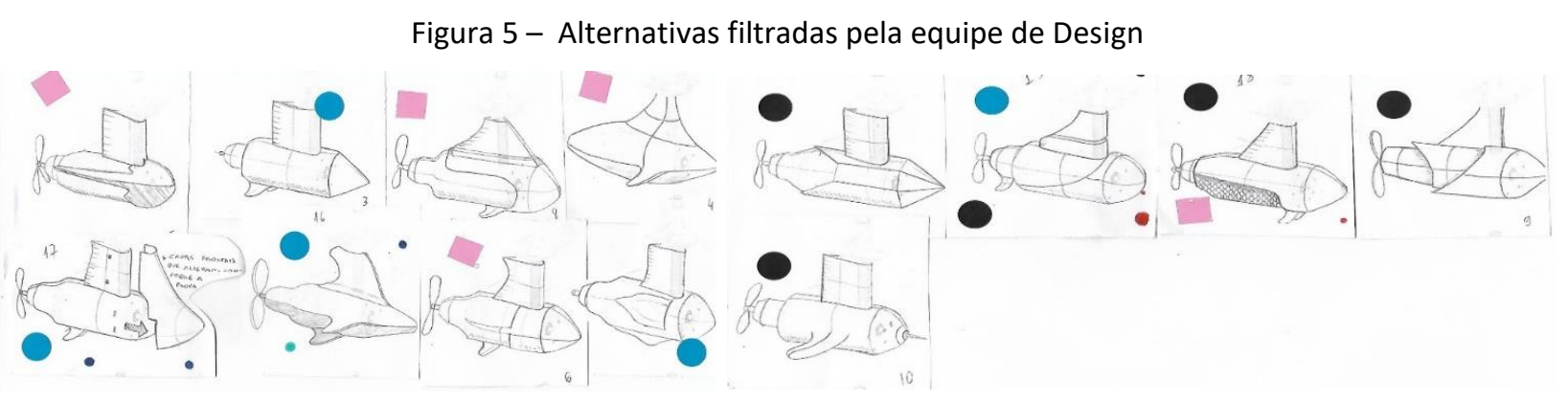

Fonte: Autoria Própria (2017)

Em seguida, reunindo a equipe de Design e as demais equipes envolvidas no projeto, realizou-se uma segunda seleção por votação, a fim de enriquecer o projeto ao acrescentar diferentes visões e opiniões. O método de votação foi aplicado da mesma forma que a anterior e, apesar de existirem alternativas comuns com a primeira votação, seu resultado selecionou apenas 10 alternativas. Cada participante teve, ainda, que justificar cada um de seus votos, explicitando as características que o levaram à escolha de cada alternativa. Essas justificativas foram registradas em anotações e em gravação de voz, estes posteriormente transcritos em um documento único. Seguem as principais observações realizadas pelos participantes:

Quadro 3 - Observações realizadas pelos participantes

\section{OBSERVAÇÃO}

1) Possuir leme inferior com sinalização de ajuste para facilitar montagem e transições suaves;

2) Apresentar modularidade;

3) Textura baseada na pele do tubarão e leme inferior longitudinal com pouca profundidade;

4) Modularidade que inclui todo o leme em uma única peça, com perfil frontal pontiagudo;

5) Corda do leme variável (comprimento variado ao longo do leme).

Fonte: Autoria Própria (2017)

A partir dos conceitos presentes nas 3 alternativas mais votadas e nas principais justificativas de escolha, a equipe de Design gerou mais 39 opções. Novamente, toda a equipe de projeto realizou uma votação, com 3 votos para cada participante. Os aspectos que levaram à escolha de cada membro da equipe foram, mais uma vez, considerados. Com isso, 3 alternativas 
sobressaíram-se, as alternativas de números 1 e 3 receberam 3 votos cada e a alternativa 32 recebeu 4 votos (Figura 6). Assim, entendeu-se que a alternativa final seria concebida fundindo suas principais características.

Figura 6 - Alternativas votadas

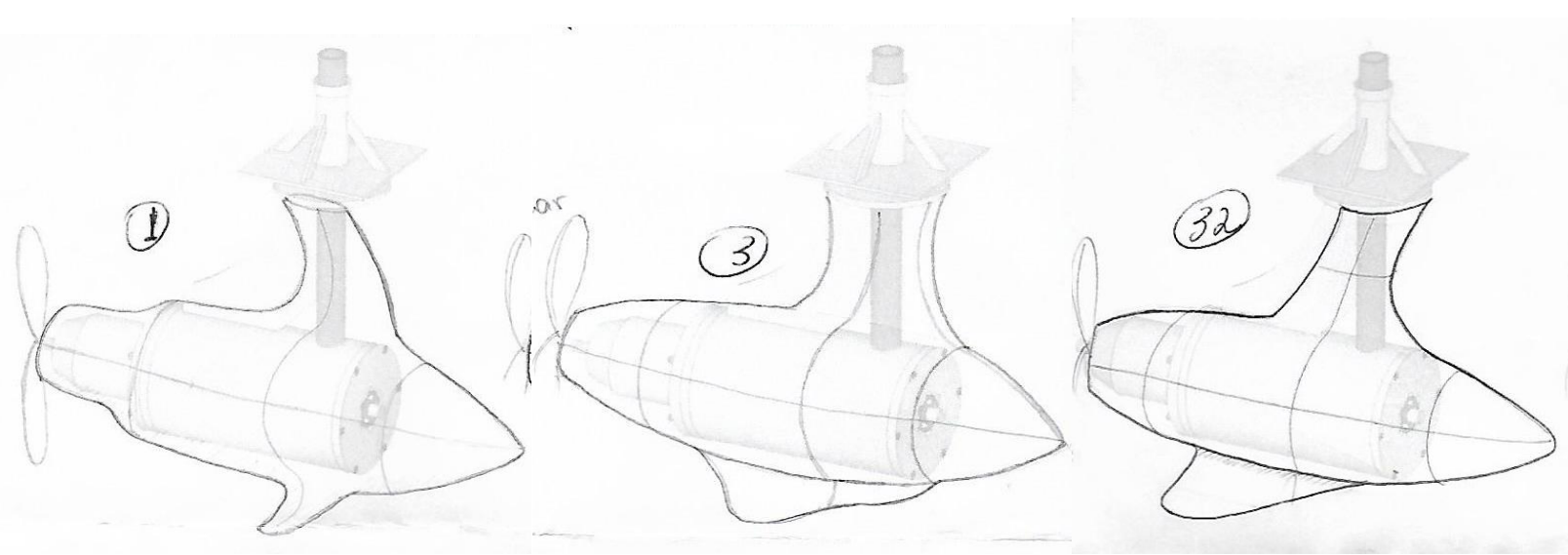

Fonte: Autoria Própria (2017)

A partir das 3 alternativas elencadas como referência foi desenvolvido um último conceito que serviu para o início das definições de dimensões e para a realização de um desenho técnico. Com essa documentação foi possível modelar a estrutura no software Solidworks (Figura 7). Após a modelagem, os métodos de fabricação e os materiais para construção do protótipo foram considerados.

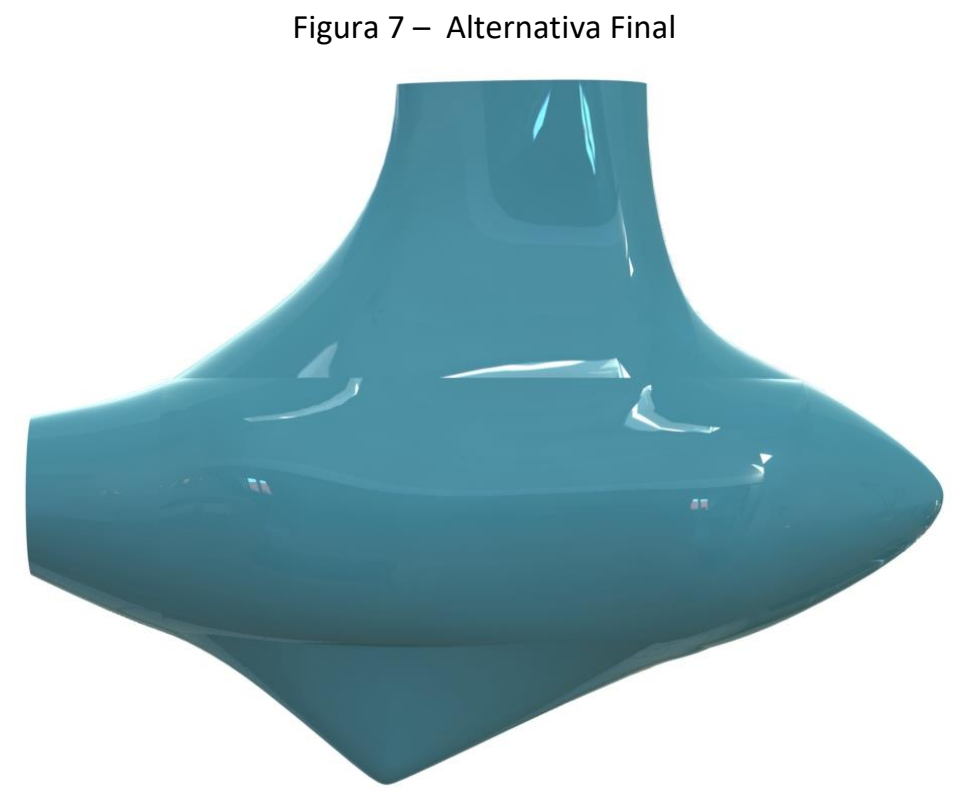

Fonte: Autoria Própria (2018) 


\section{Desenvolvimento: Pós-Concepção}

A fase de Pós-Concepção compreende as atividades realizadas após ser definida a melhor solução para o projeto, adaptando-a conforme necessário. Nesse momento foram definidos todos os parâmetros do modelo e estudados materiais específicos para o protótipo da alternativa.

Visando a possibilidade de fabricação nos laboratórios do próprio Instituto Federal de Santa Catarina (IFSC) - Câmpus Florianópolis e sua disponibilidade de recursos, o material selecionado foi a resina reforçada com fibra de vidro, já utilizada na embarcação da Equipe da Instituição e frequentemente aplicada como isolante térmico em residências. Este material possui grande resistência sob tração, apesar de ainda ser flexível (ASHBY, JOHNSON, 2011, p. 255). Além disso, este projeto funciona como um experimento e oportunidade de inovação, portanto, o uso da fibra de vidro para a construção da carenagem, diferentemente dos modelos observados na Análise de Similares, pode significar uma alternativa de material de mais fácil acesso econômico e de fabricabilidade.

Para modelar este tipo de material se faz necessário um molde, responsável por dar o formato desejado do produto. Tal molde será produzido através da impressão 3D, que segundo Monteiro (2015) apresenta vantagens como flexibilidade produtiva e simplificação dos processos, e trazem muitas expectativas sobre o seu futuro e possibilidades de mudar radicalmente a forma como os produtos serão fabricados. O processo de modelagem de fibra de vidro com base em um molde é conhecida como laminação, que, neste caso, será feita manualmente. Inicialmente, é aplicada a cera desmoldante no molde para facilitar a retirada da peça no final. Feito isso, as camadas de fibra de vidro devem ser posicionadas no molde e impregnadas com resina, assim ocorre uma reação química iniciada na resina por catalisadores, que endurece o material, dando origem a uma peça leve e resistente (MATHEUS, p. 13). A quantidade de camadas de fibra e resina aplicadas variam de acordo com a espessura final desejada. A peça moldada cura em temperatura ambiente, sem necessidade de estufa, mas em alguns casos são usadas para reduzir o tempo de endurecimento.

\section{Resultados}

A carenagem projetada para o sistema de propulsão submergível apresenta um perfil frontal pontiagudo, retirado do estudo de Biônica, atendendo ao primeiro requisito de hidrodinâmica e garantindo um melhor deslizamento dentro d'água; o leme longitudinal distribuído, com comprimento variado ao longo de sua altura, envolve o encapsulamento interno e o madre-leme da peça e possui maior altura na parte inferior do que em seu hélice, impedindo que este encoste no fundo do mar. Sua presença, ainda, auxilia a manter o sistema alinhado com a direção do barco.

O uso da fibra de vidro, atende ao requisito de proteger contra corrosão causada pela água salina e é resistente a possíveis impactos; cumpre com a meta de baixo custo de produção; e possibilita o desenvolvimento de peças que servem como agentes facilitadores do processo de montagem e desmontagem sem causar prejuízos ao produto. A estrutura da carenagem é modular e conta com apenas duas partes, unidas por parafusos e encaixes pré-estabelecidos (Figura 8), sendo a sua parte frontal substituível conforme a modalidade de prova do Desafio Solar Brasil, visto que cada prova apresenta requisitos hidrodinâmicos diferentes - provas de velocidade são diferentes daquelas de manobrabilidade, por exemplo. Neste projeto desenvolveu-se apenas um dos módulos previstos, adequado especificamente para provas de velocidade. 
Figura 8 - Perfil Frontal Pontiagudo, Leme e Estrutura Modular.

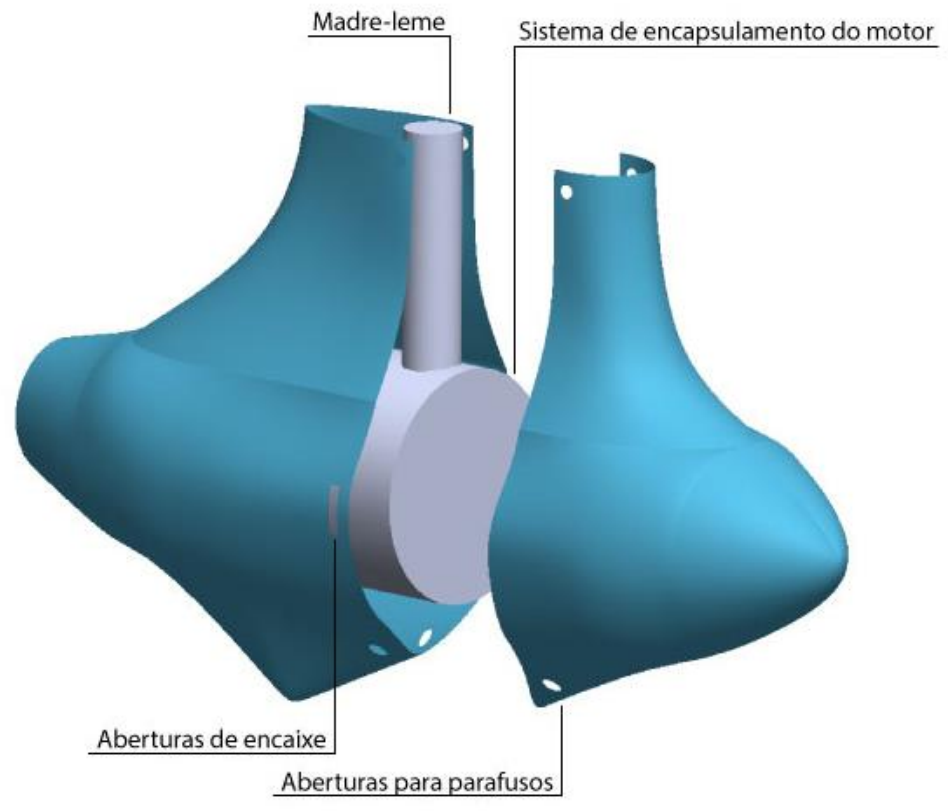

Fonte: Autoria Própria (2018)

\section{Considerações Finais}

A carenagem do sistema de propulsão submergível do barco solar da Equipe Zênite projetada atende ao objetivo proposto inicialmente, protegendo contra os efeitos da água salina e possíveis impactos, adequando-se por meio do sistema modular às diferentes demandas hidrodinâmicas das provas do Desafio, bem como tornar fácil o processo de montagem e desmontagem por meio de encaixes e parafusos. Como o projeto da carenagem efetivou-se em paralelo com os projetos dos sistemas mecânicos e elétricos desenvolvidos pelas equipes das Engenharias, mostraram-se eficientes o método e as ferramentas utilizadas pelo Design para manter o direcionamento e foco do projeto com vistas à inovação, facilitando a comunicação entre os integrantes e tornando visíveis as necessidades existentes.

Para a obtenção de dados específicos que possibilitem o avanço do design da carenagem, recomenda-se que em futuros trabalhos sejam realizados testes na ferramenta Flow do Software SolidWorks, em que o pesquisador poderá identificar possíveis aprimoramentos no modelo em termos de hidrodinâmica.

\section{Referências}

ARAÚJO, Rodrigo B. de; SILVA, Marivaldo W. S.; NASCIMENTO, Adriana de S.; ARRUDA, André O. Desenvolvimento de Quilhas para Pranchas de Surf com Base na Biomimética Utilizando Materiais Alternativos. In: Congresso Brasileiro de Pesquisa e Desenvolvimento em Design, 11., 
Gramado, 29 a 2 out. 2014. Anais do 11 ㅇ Congresso Brasileiro de Pesquisa e Desenvolvimento em Design. Gramado: UFRGS, 2014. p.2068-2077.

ASHBY, Michael; JOHNSON, Kara. Materiais E Design: Arte E Ciência Da Seleção De Materiais No Design De Produto. Rio de Janeiro: Editora Elsevier, 2010.

BATISTA, Flabio A. B.; CAZANGI, Humberto R.; GEHLEN, Alexsandro; MANZOLI, Arturo; FERREIRA, Bruno E.; TOMASSI, Bruno P. D. T.i; GARCEZ, Gabriel N.; CARDOSO, João A.; AUGUSTO, Marcio A.; OGLIARI, Natan O.; PACHECO, Nícolas. Embarcação Solar de Pequeno Porte Como Objeto de Pesquisa para o Desenvolvimento e Divulgação de Uso de Tecnologias Associadas à Energias Limpas. Revista Gestão \& Sustentabilidade Ambiental, nํ4, p. 411-430, 2015.

BAXTER, M. R. Projeto de Produto: Guia Prático para o Design de Novos Produtos. 2. Ed. São Paulo: Editora Blücher, 2005.

COMASSETTO, Lucas E. A Influência Das Variáveis Ambientais Na Distribuição Espaço-temporal Do Tubarão Mako (Isurus Oxyrinchus) No Oceano Atlântico Sul E Equatorial. Recife. Universidade Federal Rural de Pernambuco, Recife, 2016.

DZINDOLET, Paul B. P. e Mary T. Social Influence Processes in Group Brainstorming. Journal of Personality and Social Psychology, v. 64, no 4, p. 575-586, 1993.

FUERBACK, André. Sistema de encapsulamento de um motor elétrico para um sistema de propulsão submergível. Florianópolis: IFSC, 2017.

INTERNATIONAL ENERGY AGENCY. Renewable Energy Technologies. Solar Energy Perspectives, $\mathrm{n}$ 이, 2011.

MATHEUS, MARCO ANTONIO. Fiberglass: Aprenda fibra de vidro. 1a ed. São Paulo, 2002.

MONTEIRO, Marco Túlio Ferreira. A Impressão 3d No Meio Produtivo E O Design: Um Estudo Na Fabricação De Joias. Belo Horizonte, Universidade Do Estado De Minas Gerais, f. 124-129, 2015.

NICKEL, E. M.; FERREIRA, M. G. G.; FORCELLINI, F. A.; SANTOS, C. T.; SILVA, R. A. A. Modelo multicritério para referência na fase de projeto informacional do processo de desenvolvimento de produtos. Gestão e Produção, v. 17, no 4, p. 707-720, 2010.

OLIVEIRA, Maxwell Ferreira. Metodologia Científica: Um Manual Para A Realização De Pesquisas Em Administração. In: Catalão-UFG, 72 p.: il, 2011. (https://goo.gl/SA5cgV)

PAZMINO, Ana Verônica. Como se Cria: 40 Métodos para Design de Produtos. São Paulo: Editora Blucher, 2015.

SANCHEZ, Clément; ARRIBART, Hervé; GUILLE, Marie M. G. Biomimetism and Bioinspiration as tool for the design of innovative materials and systems. Nature Materials, $\mathrm{n} \div 4, \mathrm{p}$. 277-288, 2005.

SANTOS, Flávio A. N. V. dos. Método Aberto de Projeto para Uso no Ensino de Design Industrial. Revista Design em Foco, v. 3, no 1, p. 33-49, 2006.

YIN, Robert K. Estudo de Caso: Planejamento e Métodos. 3 ed. Porto Alegre: Editora Bookman, 2005. 